\title{
CONTROL DE CONSTITUCIONALIDAD Y LEGITIMIDAD DEMOCRÁTICA ${ }^{1}$
}

Review for constitutionality and democratic legitimacy

\section{Claudina Isabel Orunesu}

Abogada, Universidad Nacional de Mar del Plata

Doctora en Filosofía del Derecho, Universidad de Buenos Aires

Profesora de posgrado

corunesu@fibertel.com.ar https://doi.org/10.37346/opusmagna.v16i01.7

$1 \quad$ Ponencia presentada por la Dra. Orunesu en el Congreso Internacional "A las puertas del centenario de los Tribunales Constitucionales: Justicia Constitucional y Legitimidad Democrática" celebrado en la ciudad de Guatemala, los días 13, 14 y 15 de noviembre de 2015. 


\section{SUMARIO}

\section{Introducción}

1. Las concepciones de la interpretación y la interpretación constitucional

2. La objeción democrática a la justicia constitucional

3. Justicia constitucional y objeción democrática

Bibliografía 


\section{INTRODUCCIÓN}

La democracia puede ser entendida como expresión del ideal del derecho al autogobierno, es decir, el derecho de los miembros de la comunidad política a participar en la toma de decisiones públicas en un pie de igualdad, incidiendo en la determinación del resultado de esos procesos decisorios. ${ }^{2}$ Esta exigencia es la que procura satisfacer la regla de la mayoría, con fundamento en el principio de «una persona, un voto». ${ }^{3}$ El constitucionalismo, por su parte, generalmente se interpreta como sinónimo de limitación del $\operatorname{poder}^{4} \mathrm{y}$, en un sentido más específico, de las limitaciones a la regla de la mayoría, ${ }^{5}$ que se ven plasmadas principalmente en el respeto de los derechos básicos. La democracia constitucional podría ser entendida como un diseño resultante de la conjunción de estos dos elementos: si bien postula el autogobierno, también impone límites a su ejercicio.

En la democracia constitucional, la constitución establece límites de diversos tipos, pero el más importante es el que surge a partir de las declaraciones de derechos fundamentales. Para proteger jurídicamente esos derechos se los resguarda a través de una constitución con algún grado de rigidez, que impide que pueda ser modificada por el mismo procedimiento utilizado para la legislación ordinaria. Y, por sobre todo, se instituye un mecanismo de control de constitucionalidad, cuyo papel es garantizar la primacía constitucional mediante la revisión de la validez de las normas dictadas por el legislador. Para diversos autores, el control de constitucionalidad, cuando este es asignado a los jueces, es difícil de conciliar con el ideal del autogobierno. ${ }^{6} \mathrm{Al}$ habilitar la participación de órganos no representativos como los órganos jurisdiccionales en el control de constitucionalidad, confiriéndoseles autorización para establecer los alcances y el contenido de las decisiones del legislador ungido democráticamente, se estaría introduciendo, en palabras de Alexander Bickel "una fuerza contramayoritaria" en el sistema. ${ }^{7}$

\footnotetext{
2 Cf. Kelsen 1929: 21.

3 Cf. Elster 1988: 33.

4 Cf. Nino 1996: 15. Según KeLSEN esa es la función política de la constitución (cf. KELSEN 1931: 5).

5 Cf. Elster 1988: 34.

6 Véase, por ejemplo, WALdRon 1999 y TuShnet 1999. Para Waldron, además, la existencia de una constitución rígida también sería una limitación injustificada del ideal del autogobierno. Analicé las limitaciones de esta objeción en Orunesu 2012.

7 BICKEL 1962.
} 
Generalmente las cláusulas constitucionales se formulan a través de expresiones de carácter abstracto, generales y con un marcado margen de imprecisión. Además, no es raro que incluyan términos cargados de resonancias morales. Estas características dificultan el poder establecer qué es lo que dice la constitución y, por lo tanto, resiente la posibilidad de que cumpla con el papel de suministrar un criterio de corrección de las restantes normas del sistema y de las decisiones institucionales en general. También ponen en el centro de la escena a los órganos encargados de interpretar y hacer cumplir la constitución, incluso contra la voluntad de las mayorías legislativas.

Frente a ello parece sensato preguntarse si existen razones para asignar a los jueces, que en el mejor de los casos cuentan con una representatividad de segundo grado, la potestad de declarar inválidas a las normas creadas por el poder político debido a su incompatibilidad con lo establecido por la constitución y, en consecuencia, el determinar el alcance de los derechos tutelados por la constitución. De hecho, este interrogante es de larga data y se ha ido reconfigurando hasta la actualidad. ${ }^{8}$

Pero para poder tomar partido en esta discusión es importante tener en claro previamente los alcances de la objeción democrática contra el control judicial de constitucionalidad. Sostendré que para poder ofrecer una respuesta satisfactoria a la pregunta de naturaleza normativa sobre si, o en qué medida, los jueces están legitimados en el marco de una democracia a ejercer el control de constitucionalidad, es necesario previamente establecer los límites de la objeción, conectando sus argumentos centrales con las diferentes concepciones de la interpretación y con las características de los diseños institucionales en particular. Para ello, primeramente ofreceré un panorama, bastante simplificado, sobre diferentes concepciones de la interpretación del Derecho en general, y de cómo desde ellas se concibe la tarea de interpretar a los textos constitucionales. No es mi intención aquí profundizar en los aspectos deficitarios que cada una de ellas pudiera tener, sino sólo comprender sus postulados básicos, para luego redimensionar a la luz de cada concepción los alcances de la objeción democrática al control judicial de constitucionalidad. Luego contextualizaré los argumentos centrales de la objeción en el marco de las peculiaridades de los dos sistemas clásicos de control de constitucionalidad a fin de establecer sus genuinos límites. Ello permitirá repensar la discusión en torno a la legitimidad democrática del control de constitucionalidad bajo una nueva luz.

$8 \quad$ Para un análisis de los orígenes y la evolución de la denominada objeción contramayoritaria en los Estados Unidos, véase Friedman 1998, 2000a, 2000b, 2002a, 2002b. 


\section{Las concepciones de la interpretación y la interpretación constitucional}

Para ciertos teóricos, la interpretación nunca es una actividad de conocimiento, sino que siempre involucra valoración y decisión. Para esta concepción, a menudo denominada tesis de la indeterminación radical, no hay nada parecido al significado propio de las palabras: todo texto puede entenderse en una pluralidad de modos diferentes, y cada interpretación dependerá de las valoraciones del intérprete. Así, según Guastini, los enunciados interpretativos no serían susceptibles de verdad o falsedad y compartirían con las definiciones estipulativas la misma estructura profunda. ${ }^{9}$

Para Hart, esta visión de la interpretación, a la que denominara la Pesadilla, se presenta no solo como una característica de ciertos casos difíciles de toma de decisiones judiciales, sino más bien como si la toma de decisiones judiciales fuese esencialmente una forma de creación de derecho y nunca importase la aplicación de una norma preexistente respecto de un caso. ${ }^{10}$ Esta concepción asume que nunca es posible asignar un significado a las reglas generales, ya que estas son sólo "recipientes vacíos" en los que podemos volcar el significado que escojamos $^{11}$. Los indeterministas radicales conciben a la interpretación como una tarea siempre creativa y determinante del significado y alcance de las reglas.

En el extremo opuesto se sitúa lo que podría denominarse la tesis de la única respuesta correcta. ${ }^{12}$ Para quienes sostienen esta concepción, la interpretación es siempre una actividad de tipo cognoscitivo: interpretar es descubrir el significado de los textos normativos. Así, los enunciados interpretativos son siempre susceptibles de verdad o falsedad. Por oposición a

9 Cf. Guastini, 1992: 109.

10 Cf. H.L.A. HART 1977: 123-188. La versión más tradicional de esta concepción está representada por el realismo norteamericano, que en las décadas del 20 y 30 del siglo XX reaccionó frente al formalismo jurídico de su época. Versiones más contemporáneas podemos encontrar en la corriente Critical Legal Studies y en la denominada escuela genovesa.

$11 \quad$ Altman, 1990: 19, 90-91. Para Guastini, en cambio, la tesis solo presupone que las palabras no tienen un significado objetivo o propio independiente del uso y la comprensión. Cf. GuAstini 2005.

12 Tomo de J.J. Moreso esta identificación. Véase Moreso 1997 
la tesis anterior, que sostiene que es imposible asignar un significado unívoco a las formulaciones normativas, la tesis de la única respuesta correcta sostiene que cada texto normativo tiene una interpretación verdadera y no hay espacio para la discrecionalidad judicial: los jueces nunca crean el derecho sino que lo descubren.

Un buen ejemplo para ilustrar esta concepción es la versión de corte realista ofrecida por Michael Moore ${ }^{13}$ Cuando la tesis realista se proyecta sobre el derecho, implicaría que cada enunciado jurídico sería verdadero o falso en virtud de una cierta realidad objetiva cuya existencia sería independiente de nuestro conocimiento. ${ }^{14}$ La tarea interpretativa sería, desde este punto de vista, una labor esencialmente de descubrimiento, pues consistiría en encontrar la interpretación verdadera.

Por último, la tesis de la indeterminación parcial sostiene que la actividad interpretativa es a veces cognoscitiva y a veces decisoria. Según ella, en principio es posible determinar el significado de las formulaciones normativas, pero siempre pueden surgir dudas de aplicación a los casos particulares en virtud de problemas como la textura abierta de las expresiones usadas o posibles conflictos en cuanto a sus alcances. Frente a estos casos, los jueces tendrían discrecionalidad. Para la tesis de la indeterminación parcial, a partir de la existencia de casos paradigmáticos sería posible abstraer los criterios generales de uso y establecer las condiciones mínimas para la aplicación correcta de los términos jurídicos. ${ }^{15}$ En los casos claros no existiría indeterminación, pues una vez examinado el significado de cierta formulación normativa de conformidad con las convenciones semánticas existentes, ellas resultarían suficientemente sólidas como para no arrojar dudas a su respecto. En esos supuestos, los tribunales dispondrían de una respuesta correcta, aunque podrían equivocarse a la hora

$13 \quad$ Véase, por ejemplo, Moore 1985 y 1989. A su juicio, el realismo respecto de ciertas clases de entidades implicaría diferentes tesis, entre ellas: que las entidades en cuestión existen y esa existencia es independiente tanto del sujeto como de las convenciones de la comunidad; una teoría correspondentista de la verdad; una teoría de lógica clásica; una teoría de la verdad del significado de los enunciados y una teoría causal de la referencia. La teoría interpretativa de Dworkin también podría ser considera un ejemplo de esta tesis. Ver por ejemplo DwORKIN 1977 y 1986.

14 Cf. MARMOR 1992: 90.

15 Cf. Iglesias Vila 1998: 135. 
de identificarla. En los casos difíciles, en cambio, los órganos jurisdiccionales tendrían discrecionalidad y sus decisiones no podrían ser evaluadas como jurídicamente correctas o incorrectas.

Tras este somero panorama de estas tres concepciones paradigmáticas de la interpretación, cabe preguntarse qué aproximación se sigue de cada una de ellas en lo que concierne a la interpretación de los textos constitucionales.

Para la tesis de la indeterminación radical, la práctica constitucional, quizá más que ninguna otra, vendría a confirmar que los conceptos constitucionales no son otra cosa que "recipientes vacíos". Muchas de las teorías surgidas en el seno del constitucionalismo, como el textualismo o el recurso a la intención del constituyente, serían teorías normativas que solo cobrarían sentido si se asume el hecho de la indeterminación de tales textos. Igualmente, la tarea del intérprete frente a textos que incluyen conceptos cargados moralmente, tales como las que suelen encontrarse en las constituciones, que plantean profundas controversias respecto de su significado y alcance, consistiría en elegir discrecionalmente entre las diferentes concepciones en pugna.

Para los partidarios de la tesis de la única respuesta correcta, como Moore, las cláusulas constitucionales habrían sido dictadas con el objetivo de referirse a ciertas cualidades morales reales como, por ejemplo, la igualdad, y sería tarea de aquellos que interpreten la constitución "describir" esa realidad. Para esta concepción, las definiciones mediante criterios o ejemplos paradigmáticos cuanto mucho serían derrotables, en el sentido de que estarían sujetas a ser corregidas a la luz de una mejor teoría acerca de la naturaleza del género de la cosa a la que las palabras se refieren. ${ }^{16}$

Por otra parte, desde una perspectiva como la de Moore, solo asumiendo el realismo moral se podría justificar el control judicial de constitucionalidad en una democracia:

El realismo moral puede dar sentido a algunas de nuestras prácticas de adjudicación [...] cosa que no pueden hacer ni el convencionalismo ni el

16 Cf. Moore 2000: 100 
escepticismo moral. Considérese un solo ejemplo, la práctica del control judicial de constitucionalidad en el derecho constitucional americano en tanto ese control es ejercido al interpretar la carta de derechos y las enmiendas de la guerra civil. Un realista moral puede ver esas enmiendas como refiriendo a derechos preexistentes que todas las personas poseen. Cuando hoy un juez realista moral invalida la expresión de la voluntad de la mayoría que supuestamente está representada en una ley, lo hace en el nombre de algo que está más allá de su poder de cambio y más allá del poder de cambio del consenso de la sociedad. Su justificación para ir en contra de la mayoría no es que sus sentimientos son diferentes de los de la mayoría, ni que algún consenso del pasado de una supermayoría es diferente del consenso actual que una ley representa. Su justificación para el control judicial de constitucionalidad es contundente, y también lo es su forma de practicarlo: buscará descubrir la verdadera naturaleza de los derechos a los que se hace referencia construyendo la mejor teoría que pueda mostrar acerca de la naturaleza de la igualdad, la naturaleza de la libertad, etc. ${ }^{17}$

La tesis de la indeterminación parcial, a su turno, resalta que el significado de las formulaciones normativas se da en el marco de las convenciones y prácticas que constituyen el lenguaje de la comunidad. En muchas ocasiones esas convenciones respecto de los términos en cuestión se encuentran más o menos consolidadas y su significado estará determinado. Pero en otras existen dudas respecto del sentido que debe asignárseles. Y esto porque, como indica Moreso, la semántica de los lenguajes naturales no es completamente estable y puede en determinado momento existir desacuerdos acerca del significado de una formulación. Y lo mismo sucede con la semántica de la constitución y la del derecho en general. ${ }^{18}$

17 MoORE 1992: 229. "Seguir verdaderamente la 'voluntad de la (súper) mayoría’ será buscar las respuestas correctas a las preguntas acerca de cuál es el derecho de las personas al debido proceso, cuál es su derecho a la libertad de expresión y religión, qué castigos son crueles, y cuestiones similares" (MOORE 1985: 394. La traducción me pertenece). 


\section{La objeción democrática a la justicia constitucional}

¿Debe asignarse a los jueces competencia para declarar inválidas las leyes creadas por el legislador democrático cuando consideran que ellas violan lo establecido en la constitución? Para muchos defensores de la democracia constitucional, la respuesta sería afirmativa, en tanto el control judicial verse sobre las decisiones de la legislatura ordinaria y se ejercite para proteger los derechos básicos que fueran establecidos por el poder constituyente, que sería el órgano verdaderamente soberano. ${ }^{19}$ La tarea de los jueces consistiría en hacer cumplir las decisiones de la voluntad popular plasmadas en las cartas de derechos. ${ }^{20}$ Cuando un tribunal ejerce el control de constitucionalidad, protegería los derechos de los individuos y de las minorías frente a los derechos de las mayorías, ${ }^{21}$ constituyéndose así en guardián de la constitución. Según Dworkin, la democracia no exige per se que los jueces asuman el control de constitucionalidad, pero remarca que no es incompatible con él. ${ }^{22}$

En cambio, desde el enfoque opuesto, si se asume como un elemento esencial de la democracia al autogobierno, cuya expresión sería la supremacía de la legislatura, cualquier tipo de limitación a lo que ella estableciera resultaría inadmisible. En palabras de Bickel:

La dificultad fundamental consiste en que el control judicial de constitucionalidad es una fuerza contramayoritaria en nuestro sistema [...] cuando la Corte Suprema declara inconstitucional un acto legislativo frustra la voluntad de los representantes de las personas aquí y ahora, ejerce el control, no en representación de la mayoría prevaleciente, sino en su contra, Eso, sin los matices místicos, es lo que realmente ocurre [...] es la razón por la que se puede acusar al control judicial de constitucionalidad como antidemocrático. ${ }^{23}$

\footnotetext{
19 Cf. Hamilton, Madison y JAY, [1788] 2000: 332.

20 Cf. Freeman 1990: 353-354.

21 Hamilton, Madison y JAY [1788] 2000: 333. En un sentido similar, véase Dworkin 1986: 398.

22 Cf. Dworkin 1996: 17 y 32.

23 BiCKEL 1962: 16-17.
} 
Según Ely, los tribunales presentarían desde una perspectiva democrática un déficit de origen por no constituir un cuerpo electo ni responsable electoralmente. Además, su función también sería antidemocrática, pues al asignárseles competencia para declarar inválida una norma emitida por la legislatura, impondrían límites a lo que el pueblo a través de sus representantes puede decidir. ${ }^{24}$

En la misma línea Waldron sostiene que, así como el establecer una carta de derechos atrincherada constituiría una limitación injustificada al legislador democrático, el permitir que los jueces tengan la última palabra acerca del contenido y alcances de los derechos implicaría privar a los ciudadanos de la prerrogativa de reflexionar libremente sobre las cuestiones que más les afectan. ${ }^{25}$

Uno de los argumentos centrales de esta objeción sostiene que la admisión del control judicial de constitucionalidad se apoyaría en una ilusión: que se puede determinar qué es lo que dijo esa "voz del pueblo" plasmada en la constitución. ${ }^{26}$ Sería imposible sostener el argumento de que los jueces solo intervienen cuando las decisiones de la legislatura son violatorias de los derechos, porque en sociedades que se caracterizan por el hecho del desacuerdo, este podría recaer incluso sobre la cuestión de si una determinada norma viola algún derecho, esto es, sobre los alcances de ese derecho y lo que él requiere. ${ }^{27}$ Los tribunales no tendrían qué defender, ya que siempre podría existir desacuerdo respecto de cuáles derechos incluir o qué derechos se encuentran realmente plasmados en la constitución. Por ello, los argumentos a favor del control judicial de constitucionalidad serían insostenibles porque "se basan en la idea de que tenemos nociones firmes acerca de lo que significa, en cada caso, respetar los derechos de todos ${ }^{\prime 28} \mathrm{y}$ cuáles sean los mejores resultados para preferir un derecho a otro. Debido a que las declaraciones de derechos a menudo se plasman en principios de carácter abierto y mediante términos con resonancias morales, se abriría una "brecha interpretativa" entre el texto constitucional y las

\footnotetext{
$24 \quad$ ELY 1980: 23.

25 Cf. WALDRON 1999: 254.

26 Cf. Gargarella 1996: 60 y 2004: 72.

27 Cf. WaLdRON 1999 351-353.

28 Gargarella 2004: 76.
} 
decisiones que lo aplican..$^{29} \mathrm{~A}$ través de la interpretación, los jueces terminarían ocupando un lugar que correspondería a la voluntad popular, instaurando una "dictadura de los jueces". La democracia constitucional sería "lo que decida la mayoría, siempre que no vulnere lo que los jueces constitucionales entiendan que constituye el contenido de los derechos básicos". ${ }^{30}$

El argumento de la dictadura de los jueces postula que el control judicial de constitucionalidad sería incompatible con los ideales democráticos porque, a través de la tarea interpretativa, serían los jueces los que establecerían el contenido y alcance de los derechos. Sin embargo, este argumento parece presuponer que los jueces deciden discrecionalmente si una norma es o no compatible con la constitución, y que las normas constitucionales de tutela de derechos fundamentales, por su formulación en términos considerablemente vagos, abstractos y con fuerte carga valorativa, no establecen por sí mismas ninguna respuesta clara respecto de la constitucionalidad de una norma o acto, sino que en todos los casos ello dependería de la decisión discrecional de los jueces. Ahora bien, esta afirmación parece comprometerse con la tesis de la indeterminación radical. Waldron, por ejemplo, sostiene que:

[...] las palabras utilizadas en cada disposición de la carta de derechos tienden a cobrar vida por sí mismas, convirtiéndose en un obsesivo eslogan que sirve para expresar cualquier cosa que uno quiera decir sobre el derecho en cuestión. ${ }^{31}$

Si esto fuera así, las constituciones no atrincherarían más que textos que admitirían cualquier significado, cuya determinación quedaría al puro arbitrio del intérprete, esto es, el juez. Dado que asumiendo la tesis de la indeterminación radical no habría ningún caso claro de inconstitucionalidad -simplemente porque tampoco habría ningún caso claro de aplicación de ninguna norma-, los tribunales tomarían siempre una decisión discrecional, de modo que la estrategia de tutela constitucional de derechos básicos consistiría en realidad en ponerse en manos de los jueces para que resuelvan como les parezca. Los textos

\footnotetext{
29 Cf. Gargarella 1996: 59.

30 BAYÓN 2000: 69.

31 WaLdRON 1999: 262. En el mismo sentido, WaLdRON 2006: 1381.
} 
constitucionales no brindarían pauta alguna ya que la atribución de significado sería un acto de pura decisión.

Si se asume esta tesis parecería que el argumento funciona, y además que lo hace de forma contundente: el establecimiento del control judicial de constitucionalidad implicaría designar a uno o más órganos para que decidan a su antojo sobre el significado de la constitución y el alcance de nuestros derechos. Sin embargo, desde esta concepción de la interpretación lo que no parece posible es restringir el alcance de la objeción al control judicial de constitucionalidad. Si el lenguaje en general, y las formulaciones normativas en particular, dependen siempre en cuanto a su significado de una decisión libre del intérprete, en nuestro caso el juez, entonces cualquier ejercicio de la función jurisdiccional en que se apliquen normas de cualquier jerarquía implicará en esta reconstrucción un ejercicio de absoluta discrecionalidad ya que quienes decidirían cuál es el contenido de las normas serían los jueces y no las legislaturas. Pero entonces, si se asume la tesis de la indeterminación radical, no hay modo de circunscribir los alcances de esta crítica al nivel de las normas de la constitución. Lo que de ella se seguiría, tal como lo han planteado algunos escépticos, es una crítica global a la manera en que entendemos ordinariamente cómo funciona el derecho.

Pero además, quien asume esta concepción de la interpretación y, a su vez, pretende justificar una democracia mayoritaria, debe enfrentar una seria dificultad para asignar un contenido al principio de la supremacía de la legislatura. Si se asume la tesis de la indeterminación radical, en realidad la actividad legislativa no podría ir más allá de un acuerdo sobre ciertos textos, susceptibles luego de cualquier interpretación, desdibujándose así el carácter supremo que se les reserva en este modelo a las decisiones legislativas, pues ellas, al igual que la constitución, no podrían establecer límite alguno al aplicador. De manera que, aunque a primera vista es desde esta concepción de la interpretación que la objeción contramayoritaria cobraría su mayor fuerza de convicción, resulta en realidad que parece incoherente sostener la supremacía de la legislatura y la crítica al control judicial de constitucionalidad bajo este presupuesto hermenéutico. 
Si se parte en cambio de alguna versión de la tesis de la única respuesta correcta, que considera que siempre es posible encontrar una respuesta objetiva a los problemas de interpretación que plantea cualquier texto normativo, la objeción de la dictadura de los jueces pierde gran parte de su fuerza de convicción ya que en tal caso la noción de brecha interpretativa, que involucra un componente creador en el intérprete, se volvería un sinsentido. El problema para la objeción contramayoritaria en este marco sería que si la constitución ofrece una respuesta correcta, los jueces no tendrían discrecionalidad sino que al ejercitar el control de constitucionalidad deberían identificar qué consecuencias se siguen de lo que establece la constitución. Así, desde una versión realista como la de Michael Moore, el juez no puede asignarle cualquier significado a un término, sino que debe hacerlo de acuerdo a la "verdadera naturaleza de la cosa" a la que se refiere la cláusula constitucional. ${ }^{32}$ De modo que la constitución no sería lo que los tribunales dicen que es, sino lo que la constitución permitiría a los tribunales decir qué es lo que ella exige de manera unívoca.

Desde luego, que haya una respuesta correcta no garantiza que se la vaya a encontrar. De manera que incluso asumiendo esta tesis se podría objetar dejar en manos de órganos no representativos tomar decisiones que conciernen a derechos fundamentales. Pero lo que se debería justificar ahora, para que la objeción funcione, son las razones por las que los jueces estarían en peores condiciones que los miembros de la legislatura para descubrir esa respuesta correcta. La objeción debería ir acompañada de un elaborado argumento que justifique la supremacía epistémica de la legislatura. Y ese argumento debe ser apto para contrarrestar el refuerzo adicional que gana bajo esta concepción de la interpretación el tradicional argumento a favor del constitucionalismo: si la constitución tiene un contenido determinado y, por ende, limita lo que la mayoría ordinaria puede decidir, ¿tiene sentido dejar en manos del órgano al que se pretende limitar el papel de intérprete privilegiado de esos límites?

32 Cf. MOORE 1985: 331. De la misma manera, para Dworkin "los jueces no deberían leer sus propias convicciones en la constitución” (DwORKIN 1996: 10). Para DworkIN la interpretación constitucional se encuentra determinada por la exigencia que denomina "integridad constitucional", según la cual ella debería ser consistente con la constitución como un todo y con las interpretaciones que le precedieron. 
Desde luego, el partidario de la crítica contramayoritaria no necesita comprometerse con ninguna de estas concepciones interpretativas: podría presuponer la tesis de la indeterminación parcial. La tarea interpretativa no sería puramente cognoscitiva ni tampoco exenta de límites. En los casos claros no existiría brecha interpretativa y los jueces solo deberían controlar que se respeten los límites fijados por la constitución para ciertos derechos básicos. Pero en los casos problemáticos los jueces sí tendrían discrecionalidad. De manera que el alcance de la objeción contramayoritaria desde este presupuesto se circunscribiría básicamente a los supuestos en los que la constitución resulta indeterminada, que por cierto no son pocos. Ahora bien, aunque bajo esta concepción de la interpretación la objeción no parece sujeta a las dificultades que se indicaron al examinar las dos concepciones alternativas extremas, sus alcances resultan ahora mucho más modestos de los que a primera vista puede parecer. Ello así puesto que dentro de este marco parece difícil considerar en abstracto la objeción sin tomar en cuenta las concretas configuraciones institucionales que asuma el control de constitucionalidad.

\section{Justicia constitucional y objeción democrática}

Quienes remarcan los déficit en términos de legitimidad democrática del control judicial de constitucionalidad han puesto su atención especialmente en sus versiones fuertes, donde los tribunales a través de su decisión pueden afectar la pertenencia de una norma dictada por el legislador democrático al sistema o su aplicabilidad. ${ }^{33}$ Así, se sostiene que las denominadas formas débiles de control de constitucionalidad son el resultado de las dudas que el control fuerte fue generando a la luz del ideal democrático. Por eso, han ido surgiendo diferentes estrategias que apuntan a que la declaración del tribunal alerte sobre la incompatibilidad de la norma en cuestión con la constitución a la legislatura, que sería el único órgano competente para decidir sobre su destino. ${ }^{34}$

33 Sobre la distinción entre pertenencia y aplicabilidad y su conexión con las declaraciones de inconstitucionalidad véase Orunesu RodrígueZ y SuCAR 2002.

34 Cf. Waldron 2018: 13. En el mismo sentido ver también van Bruggen 2019. Para un panorama de las formas débiles de control judicial de constitucionalidad véase GardBaum 2013 y Dixon 2019. Para una crítica a formas fuertes y débiles del control de constitucionalidad véase Bellamy 2010. 
Ahora bien, el control judicial de constitucionalidad fuerte puede articularse a través de diferentes diseños y en diferentes contextos institucionales. Respecto de esto último, el propio Waldron en 2006 relativizó su objeción radical tal como la delineara a comienzos de los 90', sosteniendo que sus argumentos críticos al control judicial de constitucionalidad solo serían plenamente aplicables a sociedades donde se cumplieran cuatro condiciones: 1) la presencia de instituciones democráticas funcionando razonablemente bien, incluyendo una legislatura elegida a partir del sufragio universal; 2) un conjunto de instituciones judiciales, de carácter no representativo, que también funcionen razonablemente bien para atender demandas individuales, dirimir conflictos y garantizar el imperio de la ley; 3) el compromiso de gran parte de la sociedad y de las autoridades con la idea de los derechos individuales y de las minorías, y 4) un sustantivo y persistente desacuerdo de buena fe sobre los derechos entre los miembros de la sociedad. ${ }^{35}$ Frente a estos requisitos, la primera tentación, sobre todo en el marco de la realidad latinoamericana, sería ensayar una defensa contextual del control judicial de constitucionalidad, afirmando que nuestras sociedades no cumplen con esas exigencias en su totalidad, o solo las cumplen parcialmente y, por ende, frente a esa realidad patológica la objeción democrática sería inaplicable. Sin embargo, creo que es importante tomarse en serio la objeción democrática a fin de reflexionar, incluso en contextos subóptimos (o, justamente porque son deficitarios), respecto de su viabilidad.

Si el sistema admite el atrincheramiento de las cláusulas constitucionales y, más específicamente, una carta de derechos, y no existe un órgano especialmente investido para el control de constitucionalidad, como en el modelo estadounidense, donde los efectos de la declaración de inconstitucionalidad es inter partes, solo para el caso concreto, no puede rechazarse que los jueces asuman esa potestad ya que ella no constituye sino el inevitable ejercicio de la función jurisdiccional, solo que aplicada a las normas de superior jerarquía. Quienes sostienen que toda utilización de este mecanismo es necesariamente contramayoritario y, por lo tanto, debe abolirse o limitarse severamente, parecen no advertir esta circunstancia.

35 Cf. WALDRON 2006: 1346. 
Ahora bien, en la justificación de la objeción existen matices. En una posible lectura, la preocupación fundamental de los críticos del control judicial se centra en que la tarea de interpretar las cláusulas constitucionales, que se caracterizan por su carácter general y abstracto, no debería quedar en manos de órganos carentes de representatividad. Así entendida, la objeción resaltaría la importancia de buscar mecanismos que democraticen la designación y el control de aquellos que deben aplicar las normas constitucionales, o que propugnen un mayor diálogo entre el poder legislativo y el judicial. ${ }^{36}$ En una versión más fuerte, la objeción contramayoritaria impugna no solo la cuestión de la carencia de representatividad del órgano judicial, sino la propia potestad para evaluar la constitucionalidad de las leyes por parte de cualquier órgano que no sea el legislativo. WALDRON al respecto sostiene:

En ocasiones, sin embargo, cuando se considera necesario rebatir las críticas democráticas contra el control judicial de constitucionalidad, los defensores de éste señalarán con orgullo hacia los Estados donde los jueces son electos. Esto sucede en ciertos Estados de los Estados Unidos. Pero incluso cuando los jueces son electos, la tarea de los tribunales normalmente no se conduce, como la de la legislatura, de acuerdo con el ethos de la representación y la rendición de cuentas electoral [...] Asúmase, por caso, que la legislatura está completamente consciente de las cuestiones de derecho a las que una determinada carta de derechos puede dar lugar, y que, habiendo deliberado sobre la cuestión, resuelve -a través del debate y el voto- establecer esas cuestiones de una manera determinada. La legislatura ha optado por uno de los bandos del desacuerdo [...] La cuestión que enfrentamos es si tal resolución de la legislatura debe ser dispositiva o si existe una razón para que sea reevaluada y quizá invalidada por los jueces. ${ }^{37}$

Quienes sostienen la objeción contramayoritaria estiman que no existen tales razones. No obstante, planteada en estos términos la crítica no se reduce a objetar que el control de constitucionalidad esté en manos de los

\footnotetext{
36 Para un análisis sobre las posibilidades de un diálogo interorgánico, ventajas y desafíos, véase Gargarella 2008, Linares 2008: 199-239, Roach 2004 y 2019, Tushnet 2008 y 2019.

37 WALDRON 2006: 1363 y 1371. La traducción me pertenece.
} 
jueces, sino que cuestiona la función jurisdiccional en su totalidad. Una vez que la legislatura ha tomado posición respecto de un determinado desacuerdo y legislado en consecuencia, del argumento parecería seguirse que no existen razones para que los jueces entiendan en esa ocasión ni en ninguna otra. Si se acepta el presupuesto de WALDRON, no hay forma de acotarlo únicamente a aquellos casos en los que se dirimen cuestiones de constitucionalidad: ningún tribunal podría evaluar los alcances de una ley infraconstitucional en relación con otra de superior jerarquía pero infraconstitucional, porque se supone que esas normas son también el resultado de una decisión consciente de la legislatura respecto de un determinado desacuerdo. La carga de la prueba ahora pasa al que rechaza sobre estas bases el control de constitucionalidad: ¿se puede lisa y llanamente prescindir en los Estados modernos de la función jurisdiccional?

Frente a este tipo de argumentos cabe recordar que si no existe un órgano específico al que se asigne competencia para ejercitar el control de constitucionalidad, este no consiste en otra cosa que el simple ejercicio de la función jurisdiccional, con la única característica diferenciadora de que las normas en juego son de rango constitucional. Obsérvese que ni siquiera quienes sostienen la existencia de alguna diferencia cualitativa entre las cláusulas que integran la constitución y las normas de inferior jerarquía -que sería el único presupuesto plausible para aceptar un trato diferente respecto de unas y otras- estiman que puede prescindirse de la función jurisdiccional. Tal como lo señalaba HART:

De hecho todos los sistemas, de maneras diferentes, concilian dos necesidades sociales: por un lado, la necesidad de ciertas reglas que, en relación con grandes áreas de conducta, pueden ser aplicadas con seguridad por los particulares a sí mismos, sin nueva guía oficial o sin necesidad de sopesar cuestiones sociales, y, por otro lado, la necesidad de dejar abiertas para su solución ulterior, mediante una elección oficial informada, cuestiones que sólo pueden ser adecuadamente apreciadas y resueltas cuando se presentan en un caso concreto [...] es menester recordar que la incapacidad humana para anticipar el futuro, que está en la base de esta indeterminación, varía en grados según los diferentes 
campos de conducta, y que los sistemas jurídicos proveen a esta incapacidad mediante una correspondiente variedad de técnicas. ${ }^{38}$

En otras palabras, se debe hacer frente a una realidad: aun con la mejor diligencia y calidad deliberativa, es posible que los legisladores a la hora de crear normas ignoren ciertos hechos o condiciones sociales y tecnológicas que cambian y evolucionan, o sobreestimen la ocurrencia de determinadas situaciones y subestimen otras. ${ }^{39} \mathrm{~A}$ esto debe sumarse la posibilidad de que al momento de aplicar las reglas generales se revelen casos que el legislador no pudo prever. ${ }^{40}$ También ocurre que en ocasiones el legislador no tiene otra alternativa que dejar determinadas cláusulas abiertas y dictar reglas que incorporan términos como «razonable»o, que proveen una cierta guía, pero permiten a la vez a los jueces y ciudadanos decidir al momento de la aplicación cuestiones que no podrían adecuadamente resolverse por anticipado. De manera que, a la hora de diseñar instituciones, se debe tener en cuenta esta característica de las reglas generales: ellas no pueden resolver todo por adelantado. ${ }^{41}$

Una posibilidad para reducir la discrecionalidad del órgano de control sería optar por una constitución de detalle. ${ }^{42}$ Pero ni aun así las normas constitucionales quedarán totalmente a salvo de la intervención judicial. Por ejemplo, pueden surgir casos de conflicto entre derechos constitucionales, en los que independientemente de que las normas sean determinadas, resulta ineludible una decisión por parte de los jueces. El procedimiento judicial sirve para remediar los errores o imprevisiones que surgen del nivel de generalidad en el que las legislaturas deliberan. Aun contando con un modelo ideal de legislatura como el que propone WALDRON, que por ejemplo sea más sensible a cuestiones particulares, introduciendo audiencias públicas antes de la sanción

38 Hart 1961: 162-163. En el mismo sentido Hart 1961: 269-271.

39 Así, los legisladores en ocasiones actúan en respuesta a hechos sobresalientes y cercanos que distraen su atención de otras consecuencias y probables circunstancias subyacentes a la cuestión. Los legisladores pueden tomar decisiones que dependan de forma exagerada de un hecho particular, sobreestimando su papel dentro del rango más amplio de hechos. Cf. Schauer 2006: 893-899.

40 Cf. Schauer 1991: 89-90.

41 Para un análisis del carácter sub y sobre incluyente de las reglas, véase ScHAUER 1991: 89-91.

42 Cf. KELSEN 1931: 34-37. 
de las leyes o estableciendo la obligación de consultar a los agentes afectados por determinadas leyes, siempre pueden surgir casos problemáticos en la aplicación de las normas.

En este contexto, el advertir que el control de constitucionalidad no es otra cosa que el ejercicio de la función jurisdiccional aplicada a las normas de mayor jerarquía, no tiene por qué implicar que en estos casos la protección de los derechos de jerarquía constitucional se traduzca necesariamente en una tan amplia delegación al poder judicial para establecer lo que los derechos son. El sistema podría, por ejemplo, prever que los jueces deben autolimitarse a la hora de invalidar por inconstitucional una norma, asumiendo la presunción de constitucionalidad de las leyes dictadas por el legislador, y que solo en casos en que la inconstitucionalidad sea manifiesta se puede avanzar sobre la validez. ${ }^{43}$ Pero además, en el caso del sistema americano, la declaración de inconstitucionalidad tiene una importante limitación: solo se declara respecto del caso concreto, y en virtud de esta limitación se podría argüir que parece ser más respetuosa de las atribuciones del poder legislativo. ${ }^{44}$

En conclusión, en el marco de un sistema en que no está individualizado el órgano de adjudicación que puede ejercer el control, la objeción contramayoritaria en su versión más fuerte deja de ser una crítica al control judicial de constitucionalidad para convertirse en una crítica a la función jurisdiccional en general, de la que es imposible prescindir.

Cabe ahora analizar cómo afectan las objeciones contramayoritarias a los sistemas que sí prevén un órgano expresamente designado para el control de constitucionalidad, como sucede en aquellos países que cuentan con un tribunal constitucional y un régimen concentrado de control. En general en

43 Por ejemplo, las Constituciones de Suecia y Finlandia declaran expresamente que solo puede inaplicarse una norma cuando ella es manifiestamente inconstitucional. Esta es la doctrina que defendía Thayer, quien postulaba la obligación de los tribunales de asumir una actitud de deferencia fuerte hacia el legislador (cf. THAYER 1893).

44 Existen otros elementos en la configuración del sistema que también pueden incidir en este mismo sentido, como por ejemplo cuáles sean las vías de acceso al control de constitucionalidad o cuál sea la fuerza vinculante de las decisiones de la Corte Suprema para los tribunales inferiores. Para un panorama sobre esta cuestión véase LiNARES 2008: 147- 197. 
tales sistemas, mientras que el tribunal constitucional es el único que puede invalidar leyes a la luz de lo que establece la constitución, los tribunales ordinarios tienen a su cargo la aplicación de la legislación a casos concretos. La opción por tribunales constitucionales en un primer momento estuvo vinculada con la necesidad de garantizar la seguridad jurídica, evitando las discrepancias que entre diferentes tribunales pudieran surgir cuando se ventilan cuestiones constitucionales. En la actualidad, se ha señalado además que este modelo tendría otras ventajas. Así, según Ferreres Comella, una de sus cualidades residiría en la posibilidad de diseñar de manera diferenciada el tribunal constitucional y la justicia ordinaria. Este sistema permitiría reservar para la justicia ordinaria un sistema menos politizado, vitalicio y más sensible al principio de división de poderes, mientras que para la justicia constitucional se podrían instrumentar mecanismos de selección de sus miembros directamente dependientes de las mayorías parlamentarias, estableciendo su elección a través de estas y por períodos cortos, no vitalicios, aumentando así el grado de convergencia con el poder legislativo. El unificar el control en un único tribunal permitiría además que el poder político calibre con mayor claridad el grado de resistencia judicial frente a una ley por razones de su inconstitucionalidad, y así oponer sus propios argumentos a esa resistencia, ya sea a través de la opinión pública o promoviendo la reforma constitucional para rechazar los criterios del tribunal. ${ }^{45}$

Para los partidarios de la objeción contramayoritaria, estas características no resultan suficientes para otorgarles credenciales democráticas a los tribunales constitucionales. En primer lugar, porque la designación o confirmación por representantes electos de los miembros del tribunal constitucional no podría asimilarse a las credenciales democráticas de quienes son elegidos directamente por el voto popular. ${ }^{46}$ En segundo lugar, porque el núcleo central de la objeción, esto es, que los tribunales no deben declarar la invalidez de normas dictadas por el parlamento porque ello significaría sustraer el poder de los órganos representativos, parece no solo mantenerse incólume frente a los tribunales constitucionales sino cobrar mayor fuerza, porque la declaración de inconstitucionalidad tiene en este sistema efectos erga omnes. ${ }^{47}$.

\footnotetext{
45 Cf. Ferreres Comella 2003: 80-87 y 2009.

46 Cf. WALDRON 2006: 1394.

47 Cf. WALDRON 2006: 1354.
} 
Pese a esto, en lo que respecta a la insuficiente representatividad de los tribunales constitucionales en comparación con las legislaturas, como ya señalé, sin duda podrían existir mejores mecanismos de designación tanto de los miembros de los tribunales constitucionales como de los jueces en general. En este caso existe un mayor esfuerzo por reflejar la voluntad política de la sociedad en la conformación del tribunal en comparación, por ejemplo, con el tradicional objeto de la crítica, esto es, el sistema de estilo estadounidense. De todos modos, el problema de la mayor o menor representatividad de los mecanismos de selección debería independizarse conceptualmente de la cuestión de si los tribunales constitucionales deben o no tener la potestad de declarar inválida una norma por inconstitucional. Pueden existir, del mismo modo, sistemas más y menos representativos para la selección de los miembros de las legislaturas, pero esto no puede constituir un argumento contra la asignación a un órgano colegiado de la potestad de crear normas generales.

Encuantoalcarácterergaomnesdelasdeclaracionesdeinconstitucionalidad en los sistemas de control concentrado, en primer lugar debe recordarse que la circunstancia de que se invista a un órgano específico para el control de constitucionalidad no necesariamente implica que sus decisiones al respecto tengan carácter erga omnes. Esa asociación es sólo contingente y se registran muchos casos en los que las decisiones de los tribunales constitucionales no revisten tal carácter. ${ }^{48}$ Pero, además, se podría argumentar que cuando se opta por un diseño que admite la declaración de invalidez erga omnes, lo que se busca preservar la seguridad jurídica, esto es, que individuos que se encuentran en situaciones similares reciban un trato igualitario en virtud de la valoración única que efectúa el tribunal designado respecto de la constitucionalidad de la norma que le es aplicable. En otras palabras, la seguridad jurídica vendría a preservar en el plano de la aplicación de las normas judiciales el principio de igual consideración y respeto, que en los sistemas de control difuso se vería afectado pues podría darse el caso que individuos que se encuentran en situaciones semejantes no reciban un trato igual como consecuencia de que diferentes jueces juzgaron de manera disímil la constitucionalidad de las normas aplicables. Ahora bien, recuérdese que una de las razones que los partidarios de

$48 \quad$ Véase LinAREs 2008: 249-250 donde se efectúa un relevamiento de los efectos inter partes o erga omnes de las sentencias en diferentes sistemas de control de Latinoamérica. 
la objeción contramayoritaria ofrecen para privilegiar a la regla de la mayoría está dada precisamente por el respeto de este principio. Siendo ello así, desde este punto de vista se podría sostener que un diseño institucional que inviste a un tribunal constitucional de la competencia para declarar la invalidez erga omnes de las leyes no es más deficitario desde el punto de vista democrático que los sistemas de control difuso. Es más, en esta línea se podría argumentar que el cargo de antidemocrático contra este diseño pierde parte de su fuerza, ya que tanto la conformación del tribunal como los efectos que se asignan a sus decisiones revelan claramente un esfuerzo por consagrar un control de constitucionalidad más apegado a los ideales democráticos.

Por supuesto, se puede sostener frente a este tipo de defensas que ellas, en el mejor de los casos, solo logran atenuar la intensidad de la objeción democrática y resultan insuficientes para justificar que los jueces, a través del control de constitucionalidad, tengan la última palabra institucional. Quienes se toman en serio la objeción contramayoritaria sostienen que en un sistema genuinamente democrático esa última palabra debe quedar siempre en manos del Parlamento y nunca en manos de los jueces. ${ }^{49}$ Debe advertirse, sin embargo, que esta tesis, sus alcances y específicamente qué se entienda por «tener la última palabra institucional», tampoco puede analizarse sin considerar cuál es la teoría interpretativa que se presupone y cuál es el sistema específico de control que se tiene en mente. En un sistema de control concentrado donde, como diría Kelsen, el tribunal parece asumir el papel de legislador negativo, el argumento de la última palabra parece tener fuerza. Pero normalmente la formulación de este argumento parece presuponer, como por ejemplo lo hace Waldron, que el desacuerdo acerca de si una determinada norma viola ciertos derechos es inevitable en todo caso, esto es, se asume la tesis de la indeterminación radical que, como señalé antes, existen fuertes razones para rechazar. Si ese no es el caso y podemos por ende afirmar que en muchas ocasiones es posible diferenciar entre interpretaciones y decisiones correctas e incorrectas de acuerdo a la constitución, la afirmación de que siempre la última palabra debe tenerla el Parlamento debería ser cuanto menos matizada. Puede darse la situación de que el Parlamento haya dictado una norma claramente inconstitucional y que el tribunal constitucional correctamente la haya declarado inconstitucional. ¿Tendría sentido en ese caso darle la última palabra al Parlamento? Si aceptamos

\footnotetext{
49 Véase también TushNEt 2006.
} 
que casos como ese pueden darse, la obligatoriedad del reenvío al Parlamento para que tenga la última palabra podría generar dos situaciones. Si frente al reenvío el Parlamento insiste en su decisión inconstitucional, estaríamos frente a una situación crítica desde el punto de vista institucional en tanto se acepte que lo que es suprema es la Constitución y no el Parlamento. Por otro lado, si la decisión del tribunal ofrece razones de tal peso que llevan al Parlamento a aceptar su error, la decisión luego del reenvío sería puramente formal.

Pero además, este argumento parece suponer que la naturaleza de la última palabra en uno u otro órgano es equivalente, y que la única diferencia radica en la presencia o no de accountability electoral en uno u otro órgano. Sin embargo, esta simplificación es equivocada. En los sistemas modernos las decisiones de los jueces solo pueden ser consideradas válidas si se encuentran debidamente justificadas. Eso conlleva una exigencia muy fuerte para los jueces: deben brindar razones de sus decisiones y se podría decir que ese es uno de los fundamentos centrales del carácter autoritativo de las decisiones judiciales en el Estado de Derecho. En cambio, las legislaturas no están obligadas a ofrecer razones o justificar el porqué de una prescripción..$^{50}$

De la misma manera, si se asume la teoría de la indeterminación parcial, que circunscribe la discrecionalidad de los jueces a los casos problemáticos de interpretación en conjunción con un sistema donde la declaración de inconstitucionalidad se dicta únicamente para el caso concreto y sólo tiene efectos inter partes, es difícil identificar en qué podría consistir en tal caso afirmar que el Congreso debe tener la última palabra institucional sin desnaturalizar sus funciones y el principio de división de poderes. Pero, otra vez, eso solo podría circunscribirse a ciertos casos problemáticos de interpretación.

Si se considera relevante para la evaluación de las instituciones y las decisiones que ellas posean legitimidad democrática, y esta última es entendida principalmente en términos de la presencia de credenciales electorales y responsabilidad política, es claro que el control judicial de constitucionalidad de las leyes siempre será en mayor o menor grado deficitario.

Ahora, se podrían proponer parámetros de evaluación alternativos. Uno de ellos fue sugerido por el propio Waldron en su visita a la Corte Constitucional

50 Cf. Bulygin 1966. En un sentido similar véase Fiss 2006. 
colombiana en el año 2017. ${ }^{51}$ Allí Waldron reconoció que la noción de legitimidad democrática, en la que se basó tradicionalmente su objeción, no agota el campo significativo de la noción "legitimidad", que es susceptible de diversos núcleos significativos. ${ }^{52} \mathrm{El}$ profesor neozelandés introdujo la siguiente noción:

Yo defiendo una concepción de legitimidad bastante específica y exigente. Legitimidad se refiere a la capacidad de un sistema político y jurídico de generar respaldo para la implementación de las leyes y políticas, incluso por parte de aquellos que se opusieron a estas por razones sustanciales, es decir, por parte de aquellos que hicieron campaña en contra de esas políticas o leyes o que hubiesen votado en contra de ellas de haber tenido la oportunidad de hacerlo. ${ }^{53}$

Obsérvese que en este texto la noción de legitimidad se conecta con la totalidad del sistema institucional. En tal caso podría explorarse la posibilidad de una evaluación, en términos de legitimidad, no compartimentada de los elementos componentes de un diseño de democracia constitucional. Así, como sugiere Owen Fiss, la evaluación en términos del cumplimiento del ideal democrático de un diseño podría hacerse respecto de la totalidad del sistema, no de cada uno de sus partes componentes ${ }^{54}$ La evaluación de órganos como los tribunales constitucionales deberá hacerse en términos de la naturaleza de su relación con los elementos más representativos del sistema institucional. ${ }^{55} \mathrm{Y}$ para ello habrá que analizar la especificidad de cada diseño y responder a interrogantes del siguiente tipo: ¿La justicia constitucional es deferente al legislador? ¿Busca articular mecanismos dialógicos con todas las partes afectadas en sus decisiones? ¿Sus fundamentos se esfuerzan por brindar argumentos de razón pública? Si esto fuera aceptable, nuestras demandas democráticas hacia los tribunales constitucionales, más que remarcar su déficit representativo, apuntarán a establecer qué aporte puede hacer para garantizar que las precondiciones del sistema institucional cumplan con los ideales del autogobierno y de los derechos que una democracia constitucional busca articular.

\footnotetext{
$51 \quad$ Cf. WALDRON 2018.

52 Quizás relacionados a la manera de los "parecidos de familia" de los que hablaba Wittgenstein.

53 WALDRON 2018

54 Cf. Fiss 2006.

55 Para un intento por mostrar como la protección de los derechos humanos es una tarea compartida entre el poder judicial y las legislaturas véase KYRITSIS 2017.
} 


\section{BIBLIOGRAFÍA}

Altman, A. 1990: Critical Legal Studies: A Liberal Critique, Princeton: Princeton University Press.

Bauman R. y T. Kahana 2006: The Least Examined Branch. The Role of Legislatures in the Constitutional State, Cambridge, Cambridge University Press.

BAYON J. 2000: “Derechos, democracia y constitución”, Discusiones, núm. 1: 65-94.

Bickel, A., 1962: The Least Dangerous Branch. The Supreme Court at the Bar of Politics, Indianapolis: Bobs-Merrill. Citado por la 2da. edición, New Haven: Yale University Press, 1986.

Bulygin, E. 1966: “Sentencia judicial y creación del derecho", La Ley, vol. 124. Citado por la versión publicada en Alchourrón y BulYgin 1991: 355-369.

Dixon, R. 2019: “The forms, functions, and varieties of weak(ened) judicial review”, International Journal of Constitutional Law, Vol. 17, 3: 904-930.

Dworkin, R., 1977: Taking Rights Seriously, London: Duckworth. Citado por la traducción castellana de M. Guastavino, Los derechos en serio, Barcelona: Planeta Agostini, 1993.

1986: Law's Empire, Cambridge (Mass.): Harvard University Press.

1996: Freedom's Law. The Moral Reading of the American Constitution, Cambridge (Mass.): Harvard University Press.

ElSTER, J. 1988: “Introducción”, en Elster-Slagstad 1988: 33-48.

Elster, J. y R. Slagstad 1988 (eds.) Constitutionalism and Democracy, Cambridge: Cambridge University Press. Citado por la traducción castellana de M. Utrilla de Neira, Constitucionalismo y democracia, México: Fondo de Cultura Económica, 1999.

Ely J. H., 1980: Democracy and Distrust. A Theory of Judicial Review, Cambridge (Mass.): Harvard University Press. Citado por la traducción castellana de J. H. Ely y M. Olguín, Democracia y Desconfianza, Una teoría del control constitucional, Bogotá: Siglo del Hombre Editores, 1997.

Ferreres Comella, V. 2003: "Integración europea y crisis del modelo centralizado de justicia constitucional", Revista Vasca de Administración Pública, núm. 65, vol. 2: 73-122.

2009: Constitutional Courts and Democratic Values, New Haven, Yale University Press. 
Fiss, O. 2006: “Between Supremacy and Exclusivity”, en Bauman y Kahana 2006: 452-466.

Freeman, S., 1990: “Constitutional Democracy and the Legitimacy of Judicial Review”, Law and Philosophy, núm. 9: 327-370.

Friedman, B., 1998: “The History of the Countermajoritarian Difficulty, Part One: The Road to Judicial Supremacy”, New York University Law Review, vol. 73, núm. 2, disponible en SSRN: http://ssrn.com/abstract $=60449$.

2000a: “The History of the Countermajoritarian Difficulty, Part Three: The Lesson of Lochner", NYU Law School, Public Law Research Paper, núm. 24, disponible en SSRN: http://ssrn.com/abstract=242233.

2000b: "The History of the Countermajoritarian Difficulty, Part Four: Law's Politics", University of Pennsylvania Law Review, vol. 148, núm. 4, disponible en SSRN: http://ssrn.com/abstract=213789.

2002a: "Reconstruction's Political Court: The History of the Countermajoritarian Difficulty, Part Two", Georgetown Law Journal, vol. 91, 2002, disponible en SSRN: http://ssrn.com/abstract=312023.

2002b: "The Birth of an Academic Obsession: The History of the Countermajoritarian Difficulty, Part Five”, Yale Law Journal, vol. 112, núm. 2, disponible en SSRN: http:// ssrn.com/abstract $=312024$

GARGARELla, R., 1996: La justicia frente al gobierno. Sobre el carácter contramayoritario del poder judicial, Barcelona: Ariel.

2004: Crítica de la Constitución. Sus zonas oscuras, Buenos Aires: Capital Intelectual.

Gardbaum, S. 2013: The New Commonwealth Model of Constitutionalism. Theory and practice, Cambridge, Cambridge University Press.

Guastini, R., 1992a: Dalle fonti alle norme, Torino: Giapichelli Editore.

2005a: «A sceptical view on interpretation», Analisi e Diritto. Richerce de Giurisprudenza Analitica 2005:139-144.

Hamilton, A., J. Madison y J. Jay 1788: The Federalist. A Commentary on the Constitution of the United States, s/d. Citado por la traducción castellana de G. Velazco, El Federalista, México: Fondo de Cultura Económica, 2000.

Hart, H.L.A., 1961: The Concept of Law, Oxford: Oxford University Press. Citado por la traducción castellana de G. Carrió, El Concepto de Derecho, Buenos Aires: Abeledo-Perrot, 1977.

1977: «American Jurisprudence through English Eyes: The Nightmare and the Noble Dream», Georgia Law Review, vol. 11, núm. 5: 959-989. Citado por la versión publicada en HART 1983: 123-188.

1983: Essays in Jurisprudence and Philosophy, Oxford: Oxford University Press. 
Iglesias Vila, M., 1998: «Una crítica al positivismo hartiano: el problema del seguimiento de reglas», Analisi e Diritto. Richerche di Giurisprudenza Analitica 1998: 129-144.

Kelsen, H. 1929: Vom Wesen und Wert der Demokratie, 2da. edición, Tübingen: J.C.B. Mohr. Citado por la traducción castellana de R. Luengo TAPIA y L. Legaz y LACAMBRA, Esencia y valor de la democracia, México: Colofón, 1992.

1931: «Wer soll der Hüter der Verfassung sein?», Die Justiz, núm. 6: 576-628. Citado por la traducción castellana de R. BRIE, ¿Quién debe ser el defensor de la Constitución?, Madrid: Tecnos, 1995.

1942: «Judicial Review of Legislation. A Comparative Study of the Austrian and the American Constitution», The Journal of Politics, núm. 4: 183-200.

Kyritsis, D. 2017: Where Our Protection Lies. Separation of Powers and Constitutional Review, Oxford, Oxford University Press.

Linares, S., 2008: La (i)legitimidad democrática del control judicial de las leyes, Madrid: Marcial Pons.

MARMOR, A., 1992: Interpretation and Legal Theory, Oxford: Clarendon Press.

Moore, M., 1985: «A Natural Law Theory of Interpretation», Southern California Law Review, núm. 58: 279-398.

1989: «The Interpretive Turn in Modern Theory. A turn for the worse?, Stanford Law Review, vol. 41, núm. 4: 871-957.

1992: «Law as a Functional Kind» en GeOrge 1992: 188-242.

1995: «Interpreting Interpretation», en MARMOR 1995: 1-30.

2000: Educating Oneself in Public. Critical Essays in Jurisprudence, Oxford: Oxford University Press.

Moreso, J.J.: 1997a: La indeterminación del derecho y la interpretación de la Constitución, Madrid: Centro de Estudios Políticas y Constitucionales.

Nino. C, 1996: The Constitution of Deliberative Democracy, New Haven: Yale University Press. Citado por la traducción castellana de R. SABA, La constitución de la democracia deliberativa, Barcelona: Gedisa, 1997.

Orunesu, C. 2012: Positivismo jurídico y estado constitucional, Madrid, Marcial Pons.

Orunesu, C., J. L. Rodríguez y G. Sucar, 2002a: «Inconstitucionalidad y Derogación», Discusiones, núm. 2: 11-58.

RoAch, K., 2004: «Dialogic Judicial Review and its Critics», Supreme Court Law Review, núm. 23: 49-104.

2019 Dialogic remedies, International Journal of Constitutional Law, Volume 17, Issue 3, July 2019, Pages 860-883. 
Schauer, F. 1991: Playing by the Rules. A Philosophical Examination of Rule-Based Decision Making in Law and in Life, Oxford: Clarendon Press. Citado por la traducción castellana de C. ORunesu y J. Rodríguez, Las reglas en juego. Un examen filosófico de la toma de decisiones basada en reglas en el derecho y en la vida ordinaria, Barcelona: Marcial Pons, 2004.

2006: "Do cases make bad law?", The University of Chicago Law Review, núm. 73: 883-918.

ThAYER, J., 1893: "The Origin and Scope of the American Doctrine of Constitutional Law", Harvard Law Review, vol. 7, núm. 3: 129-156.

Tushnett, M. 1999: Taking the Constitution Away from the Courts, Princeton: Princeton University Press.

2006: Interpretation in Legislatures and Courts: Incentives and Institutional Design, en Bauman y Kahana 2006: 355-376.

2008: Weak Courts, Strong Rights: Judicial Review and Social Welfare Rights in Comparative Constitutional Law, Princeton: Princeton University Press.

2019: "Weak-form review: An introduction", International Journal of Constitutional Law, Volume 17, 3: 807-810.

VAN BRUgGen, M. 2019: "Democratic rights protection: the case for weak judicial review implicit in the democratic critique of judicial review". European Constitutional Law Review, 1-22.

Waldron, J. 1999: Law and Disagreement, Oxford: Clarendon Press. Citado por la traducción castellana de Á. Quiroga y J. L. Martí, Derecho y Desacuerdos, Barcelona: Marcial Pons, 2004.

2006: "The Core of the Case against Judicial Review", The Yale Law Journal, vol. 115: $1348-1406$.

2018: "Control de constitucionalidad y legitimidad política", en Dikaion, 27, 1 (2018), pp. 7-28. 